\title{
O QUE PODE LER
}

\section{O ILETRADO?}

\section{Sylvia Leser de Mello* \\ Jerusa Vieira Gomes**}

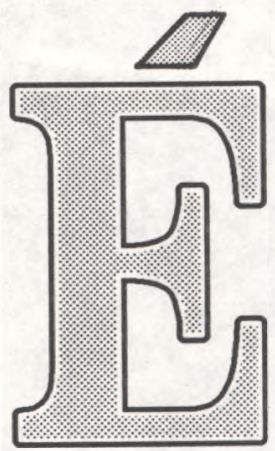

possível eliminarmos o conhecimento que temos da língua escrita e compartilharmos o mundo do analfabeto, vendo a cultura letrada como ele a vê? A resposta é negativa. Nem em fantasia podemos compartilhar a relação do analfabeto com as letras e as palavras porque, para nós, esses signos se naturalizaram de tal modo que é impossível estranhá-los. Mesmo numa língua em que as letras não são familiares a idéia básica da significação permanece. Analfabeto convive com os signos sem poder ter a experiência do seu significado, embora tenha familiaridade com eles. $\mathrm{O}$ analfabeto, sobretudo o analfabeto urbano, tem que conviver com uma deficiência extraordinária por não dominar os símbolos da escrita. Uma das faces da deficiência é a sua exclusão de um mundo ao qual não pode ter acesso, exclusão real e exclusão simbólica. "É chato gente que não sabe lê. Porque não conhece nada, nê?". Essa afirmação de uma analfabeta contém alguns dos sentimentos básicos, quanto à cultura letrada, que podemos encontrar entre os letrados. $\mathrm{O}$ analfabetismo é igual à ignorância, à burrice, à incapacidade. Os conhecimentos dos analfabetos, que são, em grande maioria, migrantes de origem rural, são relativos a uma outra ordem de coisas. Ao virem para a cidade não têm mais emprego para o que sabem e passam a crer que o único conhecimento valioso, aquele que permite ascender a uma vida melhor, aquele que torna as pessoas importantes, é o conhecimento das letras. A sabedoria letrada sempre lhes

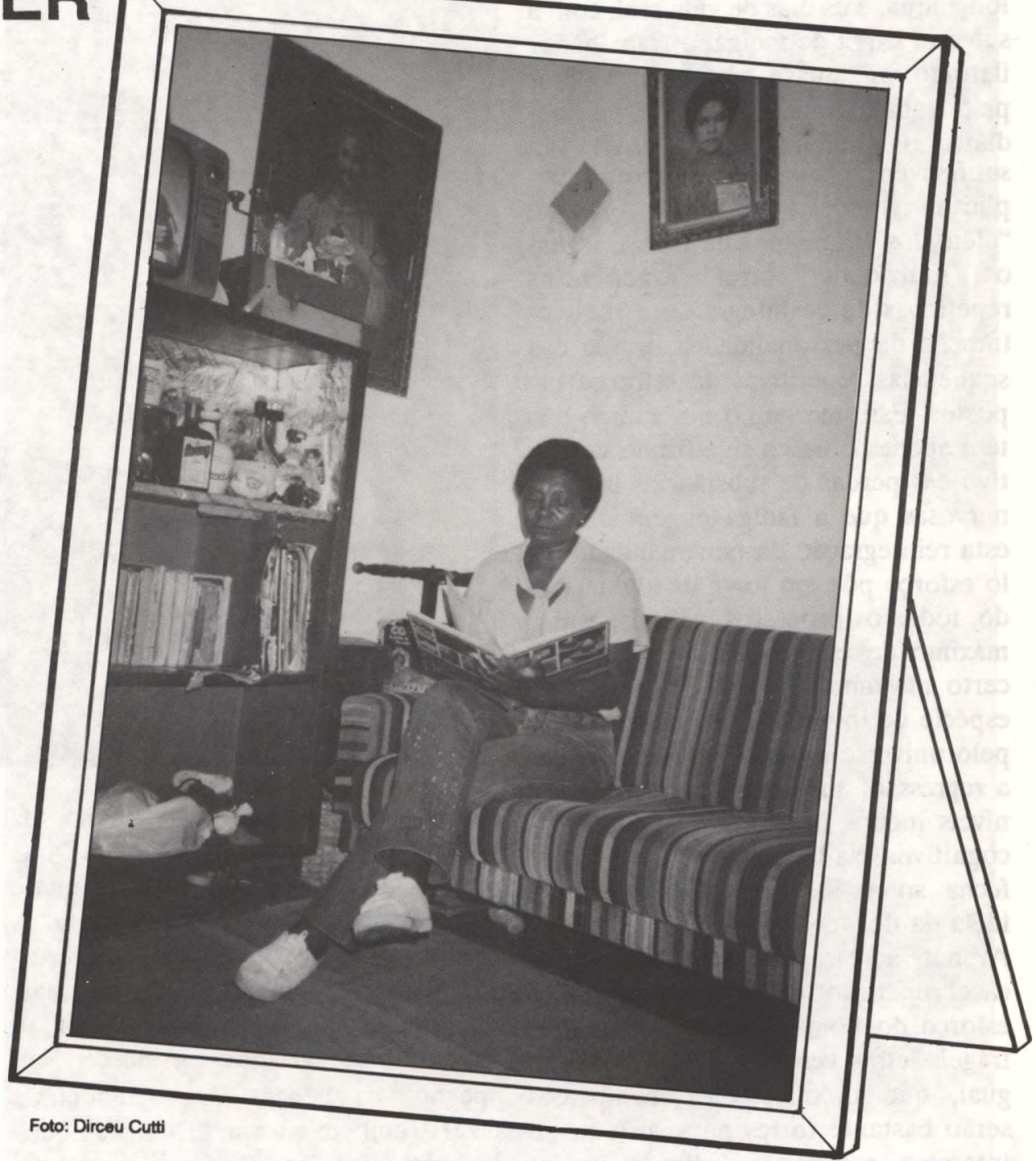

inspirou respeito, como pensa um personagem de Graciliano Ramos: "Quando seu Tomás da bolandeira passava, amarelo, sisudo, montado num cavalo cego, pé aqui, pé acolá, Fabiano e outros semelhantes descobriam-se"1. Não saber ler e escrever é, como outras marcas dístintivas da pobreza, um símbolo da condição de subalternidade. Por isso identificam o analfabetismo com a burrice, com a impossibilidade "interna" de aprender. E a "cabeça" que não serve, que não é adequada. Muitas vezes, também, justificam a dificuldade que têm para aprender atribuindo-a ao cansaço do trabalho pesado, o trabalho braçal, que "embota" a capacidade de assimilar qualquer coisa que não seja fruto da sua ação. Com essas expressões e sentimentos querem dizer que o analfabetismo é um estigma a mais a discriminar o que é e o que não é socialmente aceitável ${ }^{2}$.

Se o caminho para a superação de alguns estigmas da pobreza é o trabalho, o acesso à melhoria do trabalho passa pela escola. Ir à escola, para os adultos anaifabetos, significa acrescentar algumas horas à longa jornada de trabalho diário. Embora a vontade de ler e escrever seja uma poderosa motivação, o cansaço do trabalho, as longas horas de esforço concentrado sobre o corpo, deixam pouca energia para estabelecer as relações necessárias entre aqueles sinais, letras e sons, e ainda menos disposição para aprender a relação entre aqueles signos e a vida de trabalho que os espera de novo no dia seguinte. Ler ou não ler, escrever ou não escrever, entre o desejo que é im- 
potente, porque a sua realização é longínqua, e os dias de vida real, com a sua real carga de fadiga, o trabalhador iletrado vai, quase certamente, optar pelo trabalho que lhe garante, de imediato, o dinheiro necessário à sua sobrevivência. As atividades que implicam grandes gastos de energia, "além dos fenômenos da fadiga, fazem os indivíduos sofrer experiências repetitivas de desintegração e reestruturação da personalidade, através das sequências repetitivas de esforços impostos. Este mergulho no esforço não tem apenas o único significado destrutivo das perdas de substâncias físicas $\mathrm{e}$ nervosas que a fadiga engendra. Mas esta reintegração da personalidade pelo esforço põe em jogo, de algum modo, todos os processos mentais, pois o máximo de esforço físico implica um certo afastamento da reflexão e uma espécie de invasão do comportamento pelo universo emotivo"3. Isso significa a regressão, ao menos momentânea, a níveis menos integrados de processos cognitivos. Na labuta pesada o corpo se fecha sobre si mesmo, invocando a idéia da dor, como reconhece Hannah Arendt, acrescentando que "a implacável repetição" é que torna doloroso o esforço do homem ${ }^{4}$. Como podem as frágeis letras vencer esta batalha desigual, que prêmios ou recompensas serão bastante fortes para sustentar o interesse, superar a fadiga e limpar olhos e ouvidos da escura poeira que o cotidiano deposita neles?

Como é possível, além disso, enfrentar o profundo sentimento de inadequação do analfabeto, que se traduz como inferioridade diante de um saber quase inalcançável? Primeiramente é preciso reconhecer que o estigma da ignorância não atinge apenas o analfabeto, mas todo um segmento da sociedade. Nem por serem alfabetizados os filhos e netos dos migrantes escapam ao estigma que abarca mais fatores do que o simples saber ler e escrever. Para os mais velhos esse estigma envolve a desqualificação de um modo de vida, de uma cultura aprendida no trabalho e na manipulação direta das coisas. É a perda da tradição, do "saber fazer" do camponês - saber

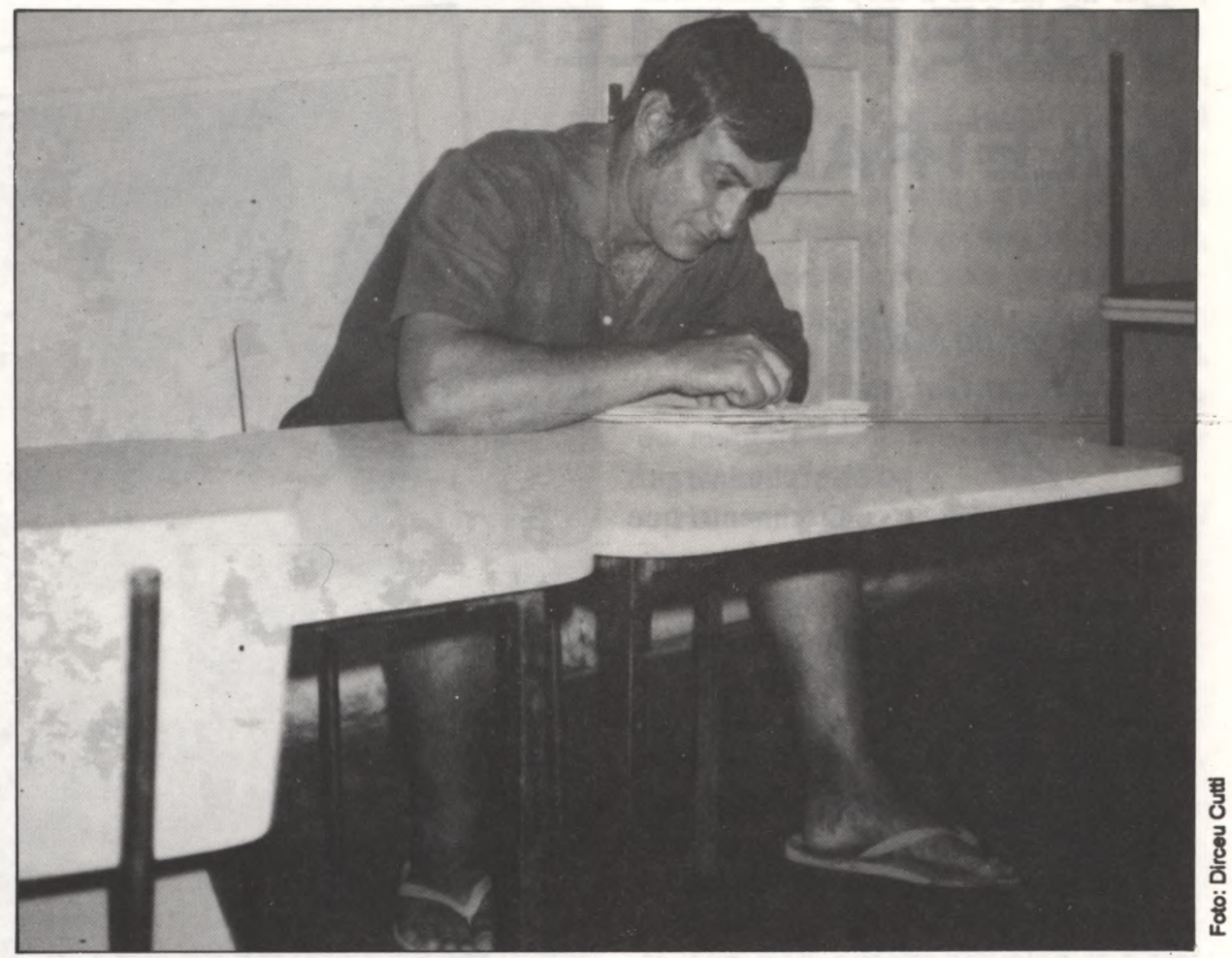

que vai do sagrado ao profano, da saúde à doença, da vida à morte. Dona Maria, que foi parteira durante quase toda a sua vida, aprendeu a fazer os partos por acaso, ou melhor, por necessidade, auxiliando a resolver um nascimento demorado. Depois, ajudou centenas de crianças a nascer, ou "pegou" os bebês, como costumava dizer. Também curava. "Eu fazia aqueles remédios, se chegasse e falasse assim: 'Eu tó com dor de cabeça...' eu fazia uma garrafada de remédio de horta e mandava e sarava aquela doença. Năo foi ninguém que ensino, foi meu dão". O conhecimento oriundo da prática com as coisas do campo ou com o universo simbolico onde aquelas práticas encontravam explicação, dificilmente tem espaço na cidade. Não é possível competir com o parto seguro e asséptico dos hospitais e muito menos com a medicina oficial dos postos de saúde. É certo que os resultados das práticas tradicionais são questionáveis e que é desejável a extensão dos benefícios a toda a população. No entanto, como os remédios são muito caros e a população é muito pobre, aquelas práticas continuam a ser amplamente empregadas, merecendo, por isso, um sério estudo quanto à sua validade. O problema é que o uso que delas faz a população é encoberto pela vergonha que têm de admitir a sua prática, tantas vezes brutalmente desqualificada pelos "letrados" da medicina oficial. Do mesmo modo, quase todos os outros aspectos da cultura "iletrada" são desqualificados no processo de adaptação do migrante à cidade. O que era conhecimento transforma-se em ignorância e o iletrado em "burro". Assim, a migração vai estabelecer uma verdadeira ruptura, onde todo um modo de vida e de trabalho se torna irrelevante. "O migrante não vive mais em um universo relativamente fechado; as atividades se dissociam; rompe-se a tela de significados interrelacionados que abrangia a quase totalidade dos modos de vida. Permanecem apenas a família e os parentes, como grupos de relações pessoais que orientam a participação no novo universo sociocultural e dentro dos quais se elaboram as novas representaçōes" $" 5$. Se quisermos responder com propriedade à pergunta proposta no título deste texto diríamos que o iletrado pode ler a sua desvalia na cidade, e a inadequação dos valores tradicionais as necessidades novas criadas pelo modo de vida urbano. 


\section{COMO O ILETRADO LÊ A ESCOLA?}

omo sugerimos antes, a escola é
vista pelo iletrado como uma porta de passagem, talvez a única de que dispõe, para uma vida melhor. Quando ela é acessível para seus filhos e netos representa uma qualificação não apenas para o trabalho, mas uma qualificação simbólica para a vida urbana. A escola dá acesso à vida social rica que o analfabeto pressente como um modo de vida especificamente urbano. Lá onde se aprende a dominar a leitura e a escrita, aprende-se também a convivência individualizada, a experiência da própria subjetividade, o modo de ser e de pertencer à cidade. Misturados às letras estão novos padrões culturais de conduta e novos valores. Em certos depoimentos de analfabetos sente-se um poder quase místico emprestado à escola, poder de transformar as relações de dominação e de vencer as diferenças de fortuna. $O$ fracasso sistemático das crianças, em lugar de mostrar como a escola é insatisfatória para acolhê-los, vem reforçar a idéia de uma incapacidade que não é mais pessoal, mas de classe social. A ausência das noções básicas da cidadania, de direito a melhores escolas, melhores condições de vida, de trabalho e de salário, transformam o acesso à escola, muitas vezes, em nova mistificação, reforçadora dos estigmas da pobreza.

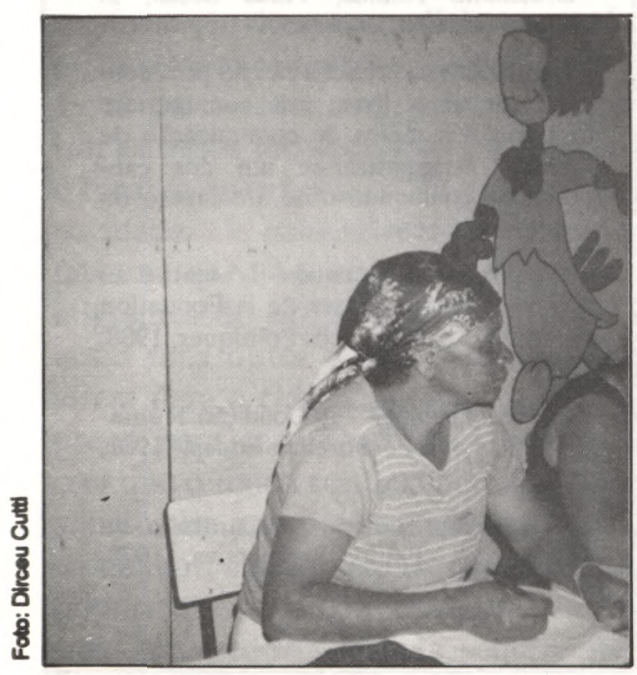

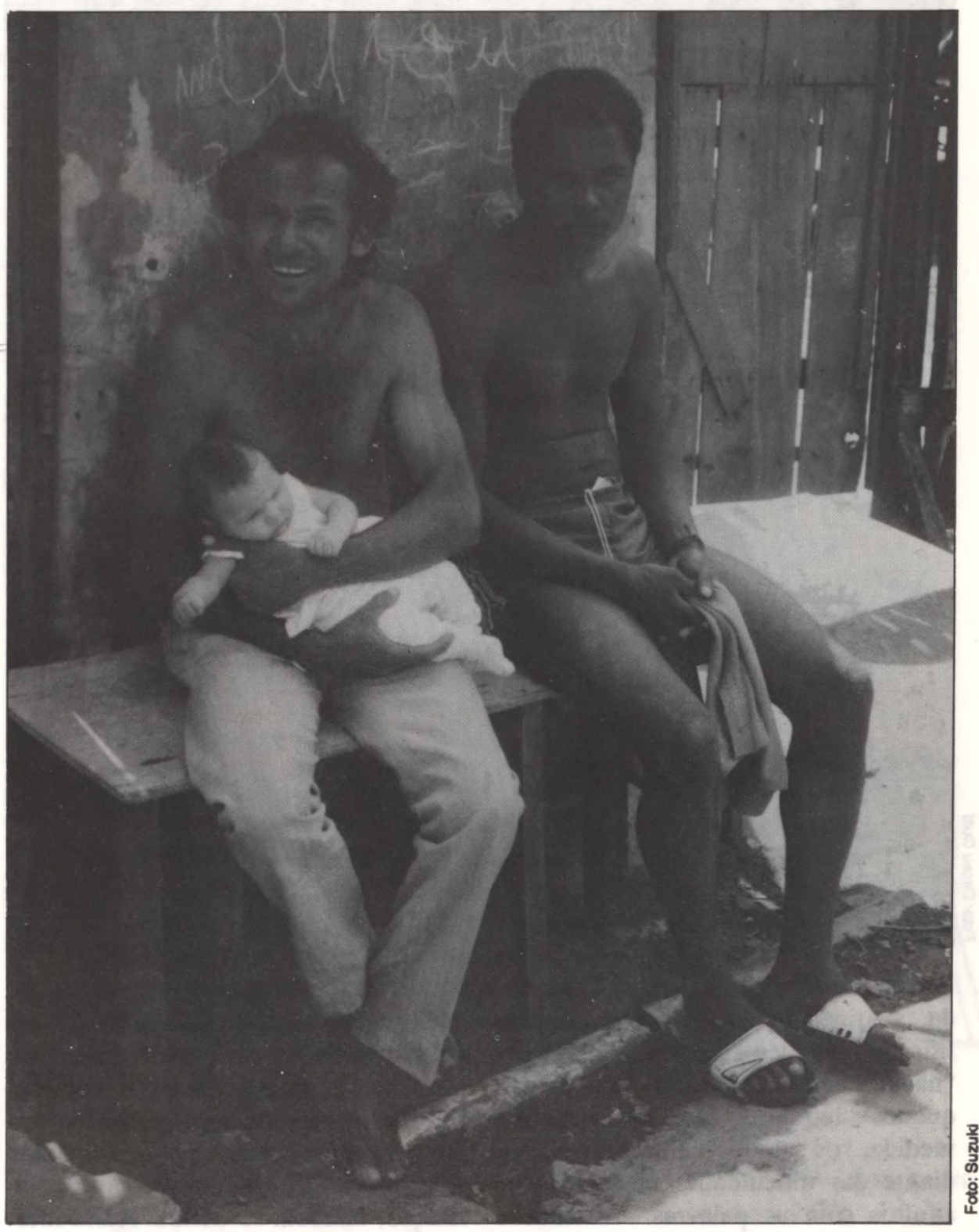

\section{COMO O FILHO DO ILETRADO LÊ A ESCOLA?}

S e, como dissemos, o iletrado $\checkmark$ pode ver na escola uma porta de acesso a uma vida melhor, não temos garantia de que seus filhos e netos a vejam assim.

A expectativa e a alegria que costumam anteceder e acompanhar o início da vida escolar de crianças de estratos médios e altos - com as exceções, sobejamente conhecidas, das crianças relutantes, cuja entrada na escola é sempre acompanhada de muito sofrimento emocional-, também são experimentadas por parte das crianças pobres, filhos e netos de iletrados.
Ao que tudo indica, nos primeiros anos escolares, às vezes reduzidos a meses, a vontade de saber - de dominar letras e números, de ler e escrever-, parece comum e suficiente para atraílas. E lá se vão orgulhosas, alegres, risonhas e esperançosas.

Em pouco tempo atingem algum domínio nessas "artes" e vão, progressivamente, sentindo-se - e até tornando-se mesmo - diferentes dos adultos ao seu redor. Desenvolvem, assim, a consciência de dominar um universo novo, estranho, vedado às gerações mais velhas de sua família, de seu meio. 


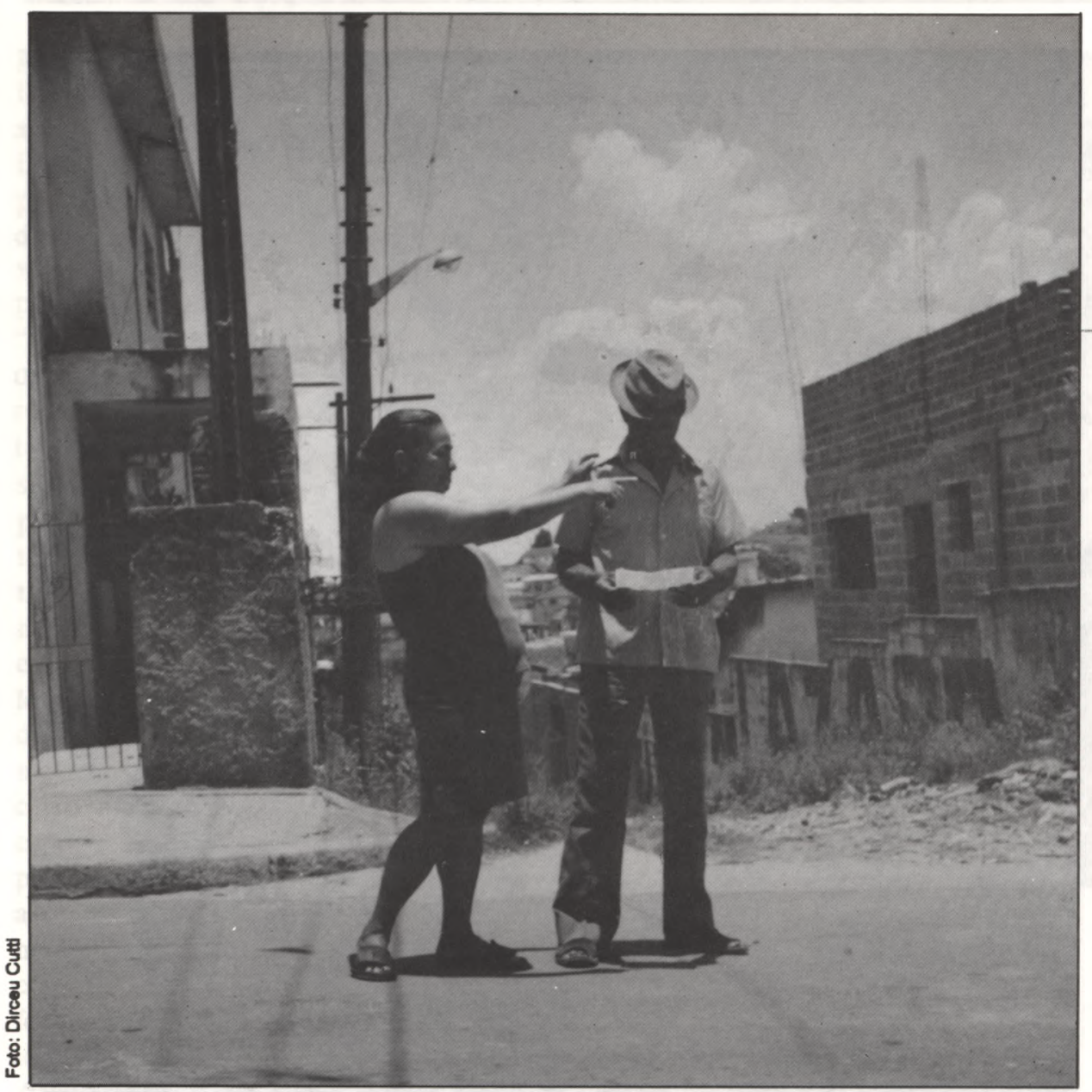

E acabam, também elas, em certa medida, sentindo-se superiores e desqualificando aqueles que, não sabendo ler, "nada sabem", enquanto eles, os pequenos "letrados" são, nessa mesma medida, "os sabidos". Chacotas e risos diante das dificuldades manifestas de adultos com as palavras - escritas e faladas -, são corriqueiros e aceitos sem constrangimentos, como algo natural e verdadeiro, até mesmo na presença de estranhos.

Porém, se para o poeta há uma pedra no meio do caminho, para essas crianças a pedra pode chamar-se escola. Eis aí uma cilada do destino: aguarda-as o dia da desilusão, o dia em que cada uma delas sentirá suas próprias dificuldades, geradas sobretudo por uma escola que, "a priori", definiu-as como incapazes para as lides do saber, à semelhança de seus pais. Assim, umas já não passam da primeira série, outras avançam um pouco mais, outras, poucas mesmo, terminam a oitava série, mas apenas raras chegarão constituir, tal qual a escola, em espaço de sociabilidade e de aprendizagem de modos urbanos de existência. Mas, antes de tudo, ele será sempre um local de trabalho, trabalho tão pesado, em geral, como aquele que os pais realizam. Por isso a escola aparece, para os jovens que nela permanecem, apesar do fracasso que se repete a cada ano, como o lugar de exercício de uma sociabilidade sem compromissos, e só de maneira muito secundária como um lugar de estudo.

Há, sem dúvida, uns poucos vitoriosos, os bem-sucedidos, que conseguem levar a cabo uma vida escolar satisfatória. Alguns chegam mesmo a realizar o sonho familiar de um trabalho mais leve, relativamente qualificado e de remuneração razoável parà os padrões nacionais. Contudo não estão a salvo: a pedra-cilada, posposta, consistirá em conciliar, no futuro, as relações familiares e sociais de origem com as novas relações de trabalho, com o novo meio.

Mas esta é já uma outra história.

* Sylvia Leser de Mello é professora do Instituto de Psicologia -USP

**Jerusa Vieira Gomes é professora da Faculdade de Educação - USP

No curso dessa trajetória de fracassos e insucessos esvai-se a esperança, instala-se a desesperança. A perspectiva de uma qualificação para o trabalho, de um trabalho melhor, de uma vida mais fácil, associada à escolarização, também se desfaz. Resta mesmo é a escola enquanto espaço privilegiado de sociabilidade: nela encontram-se os primeiros amores, aprenJem-se as novidades e a subcultura própria dos jovens. Aprende-se, enfim, o modo de vida urbano, o que implica a experiência objetiva e subjetiva de pertencer a cidade. Tudo isso acontece longe do controle doméstico, o que, sobretudo para as meninas, representa a ampliação da independência. Há, porém, ao lado do insucesso escolar, o apelo crescente ao trabalho, ao ganho imediato de algum dinheiro que, ou vai aliviar o precário orçamento familiar, ou vai permitir que o joven tenha algum dinheiro para o seu proprio consumo miúdo. Desnecessário lembrar que o local de trabalho também vai se

\section{NOTAS}

1. Mas o proprio Fabiano reconhece que seu Tomás, apesar de toda a "sabedoria", nâo "soube" enfrentar a seca: "Pois viera a seca, e o pobre do velho, tâo bom, tăo lido, perdera tudo, andava por al mole. Talvez ja tivesse. dado o couro as varas, que pessoa como ele náo podia agüentar veráo puxado". Graciliano Ramos, Vidas Secas, S. Paulo, Martins, 1973 , p.57.

2 Em 1989 , na primeira eleiçäo presiden. cial direta e livre, era comum, até mesmo nos meios de comunicação de massa, estigmatizar-se um dos candidatos, chamando-o de analfabeto ou semi-analfabeto.

3. Sainsaulieu, Renaud - L'identité au Travail, Paris, Presses de la Fondation Nationale des Sciences Politiques, 1988 . p.22.

4. Arendt,Hannah - A Condição Humana, S. Paulo, Forense-Edusp, 1981, p.112.

5. Durhan, Eunice - A Caminho da Cidade, S. Paulo, Perspectiva, 1978. p 14. 